\title{
FEASIBILITY STUDY OF OIL PALM HARVESTING USING PULSE FIBRE LASER SYSTEM WITH DIFFERENT LENSES
}

\author{
MOHD IKMAL HAFIZI AZAMAN ${ }^{1 *}$; AHMAD SYAZWAN RAMLI'; MOHD KHAIRUL FADZLY MDRADZI'; \\ MOHD RIZAL AHMAD'; MOHD RAMDHAN MOHD KHALID'; MOHD AZWAN MOHD BAKRI'; YASMIN \\ MUSTAPHA KAMIL ${ }^{1}$ and MOHD ADZIR MAHDI ${ }^{2}$
}

\begin{abstract}
Malaysia is currently experiencing a labour shortage in oil palm plantations, estimated to account for $46 \%$ of the total industrial workforce. The industry is striving to increase worker productivity by adopting new technologies using a variety of work methods. Increment of fresh fruit bunch (FFB) production in oil palm plantations has created a demand for improved harvesting technique. Some of the technologies that have been developed are practical, yet they impose several technical issues that must be solved. The potential of oil palm frond cutting using pulse fibre laser was explored. The optimisation of the laser cutting system was made using a $250 \mathrm{~mm}$ and $63 \mathrm{~mm}$ focus lens. A better cutting rate was achieved using $63 \mathrm{~mm}$ focus lens due to its shorter focal length (compared to the $250 \mathrm{~mm}$ focus lens) and capability to retain stability at a higher pulse laser frequency. The same lens was able to perform complete cuts on oil palm fronds with power and speed of 50 Watt at $500 \mathrm{kHz}$ and $1 \mathrm{~mm} / \mathrm{s}$, respectively. Good consistency was also exhibited with an average cutting rate of $0.1024 \mathrm{~mm} / \mathrm{s}$. Perhaps with further investigation and optimisation, such technique can be a viable alternative to the FFB harvesting methods that the industry is practicing today.
\end{abstract}

Keywords: laser technology, oil palm harvesting, optimisation, pulse fibre laser.

Received: 24 May 2021; Accepted: 15 November 2021; Published online: 28 January 2022.

\section{INTRODUCTION}

In 2018, the oil palm was grown over 5.85 million hectares of land in Malaysia. In return, Malaysia became the world's second-largest producer and exporter of palm oil after Indonesia, and the industry contributed RM67.50 billion to the country's export earnings in 2019 (Kushairi et al., 2019). The keys to

1 Malaysian Palm Oil Board, 6 Persiaran Institusi, Bandar Baru Bangi, 43000 Kajang, Selangor, Malaysia.

Department of Computer and Communication System Engineering, Faculty of Engineering, Universiti Putra Malaysia, 43400 Serdang, Selangor, Malaysia.

* Corresponding author e-mail: ikmalhafizi@mpob.gov.my retain premium quality, increased productivity and maximised profit are appropriate management and operating harvesting schemes of the oil palm fresh fruit bunch (FFB) (Jelani et al., 2018). Several decades ago, harvesting by using bamboo as a harvesting pole has been used, and then currently replaced by aluminium with either sickle or chisel attached to it. The development of technology is parallel to the increase of oil palm plantation in Malaysia with many harvesting technologies developed to date. Harvesting is an important activity in oil palm plantation and is estimated for about $60 \%$ of the total labour force. The efficiency of harvesting FFB plays a big role in improving the quality of harvested fruits (Jelani et al., 2003). In the past decade, the oil palm industry has adopted modern mechanisation for harvesting, mainly to increase labour productivity (Jelani et al., 2018). Over the 
years, several technologies for cutting oil palm fronds and FFB have been designed, developed and tested. Many inventions have been commercialised and introduced to the industry. The use of the Oil Palm Motorised Cutter known as Cantas has been proven to increase the productivity of harvesting FFB and reduce workers' fatigue. This machine conserves the energy of workers during the cutting operation, thus, prolonging their working hours. It can effectively harvest palm trees below $4.5 \mathrm{~m}$ (Jelani et al., 2003). For the tall palm, a mechanical harvester was invented and is able to perform all the necessary functions for harvesting activity effectively. The important role of the mechanical harvester's grapple in holding and bringing down the bunch has shown that the machine can be operated effectively (Mohd and Abd Rahim, 2014). Although some of the technologies developed are practical, several technical and capital issues as well as high maintenance costs have prompted the industry to look into new approaches (Ismail et al., 2015).

One of the many cutting technologies worth exploring is laser cutting. Laser application has been widely used in various fields especially in state-ofthe-art machinery and equipment (Ali et al., 2020; Singh et al., 2020). Laser, in general, is a device that emits light through an optical amplification process based on the stimulated emission of electromagnetic radiation. When this high intensity light beam hits the surface of a particular material, the material absorbs the radiation that will increase its internal energy, causing heat to be generated. Consequently, the heat created will partially melt or completely vapourise the material depending on the focal spot size, wavelength and power of the emitted light (Yuliansyah and Hirajima, 2012). The affected area on the surface which has lost a certain mass from the interaction with the laser beam creates the desired cut. The type of lasers that have been used for cutting are classified as carbon dioxide $\left(\mathrm{CO}_{2}\right)$ laser, solid state laser, and pulse fibre laser. Among the various laser types, fibre lasers have been deemed to be very efficient at both low and high-output power levels despite being less complex compared to other lasers (Niyibizi et al., 2014). More specifically, pulse fibre lasers are known to generate better laser beam quality at high efficiency with zero to minimal maintenance (Westphäling, 2010). The pulse regime segments the light emission into periodic impulses, delivering smaller heat-affected-zones and high spatial resolution. The pulse fibre laser is suitable for cutting biomaterials. The reason for selecting pulse laser is that energy is channelled via a temporal pulse profile different from a continuous wave (CW) beam, resulting in frond burning due to continuous energy being channelled (Figure 1). Not only that, it has the capability to cut almost any material, from textiles and bio materials to composites and leather (Caprino and Tagliaferri, 1988; Cenna and Mathew,
2002; Eltawahni et al., 2013; Steen and Mazumder, 2010). With these advantages, cutting with pulse fibre lasers is considered as one of the fastest and most versatile cutting techniques implemented across various industries (Chen et al., 2004; Ottemer and Colton, 2002).

Findings from previous investigation described the possibility of cutting plant stalks using a laser beam in contrast to mechanical cutting (Liu et al., 2011). The biomass of the plants after a certain period under standard greenhouse conditions was used to measure the effect of partial or complete cutting with a laser. The effect of laser irradiation at $1064 \mathrm{~nm}$ is less pronounced, but at this wavelength, the regrowth or continuous growth were able to be reduced (Schou et al., 2002). The laser technology has the potential to improve the oil palm harvesting, but many parameters must be considered and assessed before it can be applied in oil palm plantation (Azaman et al., 2019).

The oil palm industry is among the few industries that guarantees the nation a high rate of return on capital investment, especially for an oil palm producing country like Malaysia (Kushairi et al., 2019). Thus, seeing labour shortage as a potential critical hindrance to the continuation of oil palm production, there is a dire need of finding appropriate technology to compensate the labour loss and maintain production rate and efficiency. Success of this work will offer the industry an alternative that is capable of harvesting, as well as reduced workforce and energy usage which would boost production efficiency. It also requires less mechanical parts thus, leading to less maintenance. Besides, this will promote the advancement of conventional semi-automated harvesting techniques towards yielding optimum production without the hassle of frequent maintenance nor dependence on hard manual labour. Hence, the work is worth exploring

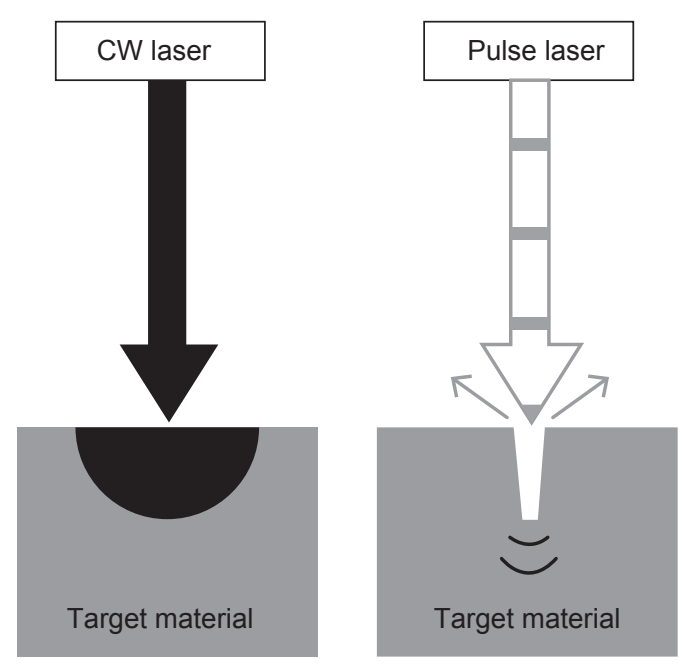

Figure 1. The difference between continuous wave (CW) laser and pulse laser cutting. 
and may contribute greatly to the advancement of oil palm harvesting technology. In this study, pulse fibre laser was explored as a potential mechanism to cut oil palm fronds. Two lenses with focal lengths of $250 \mathrm{~mm}$ and $63 \mathrm{~mm}$, respectively, were tested and cutting performance was compared based on cutting rate.

\section{MATERIALS AND METHODS}

\section{Optical Characterisation of Oil Palm Fronds}

Laser cutting efficiency depends on the overlap between the wavelength of emitted laser light and the absorption wavelength of the material. In this work, the absorption spectrum of the oil palm fronds was recorded using the experimental setup shown in Figure 2. With a supercontinuum laser (450-2400 $\mathrm{nm}$ ), the laser beam was emitted towards a slice of oil palm frond sample and the remaining transmitted light was directed to an Optical Spectrum Analyser
(OSA). The size of each slice was an average of $0.3-1.0 \mathrm{~mm}$ of the samples.

Based on the findings in Figure 3, the absorption spectrum ranged from $900 \mathrm{~nm}$ to $1600 \mathrm{~nm}$. This is mainly contributed by the high amount of cellulose, hemicellulose and lignin within the frond. The flat absorption spectrum from $900 \mathrm{~nm}$ to $1300 \mathrm{~nm}$ refers to the cell structure as previously reported (Quintero et al., 2011). The peaks within 1400$1500 \mathrm{~nm}$ indicate water absorption which also coincides with the previous report (Quintero et al., 2011). As previously reported, the investigated optical properties and characteristics of the oil palm fronds are similar to other leafy vegetables with high moisture (Dawson et al., 1998). The understanding of the cellulose absorption spectrum will play a huge part in determining the optimum laser operation wavelength for laser cutting (Heiderscheit et al., 2019; Parvin et al., 2012). Based on the experimental findings, a working wavelength of $1064 \mathrm{~nm}$ was selected which coincided with the emission wavelength of ytterbium-doped fibre laser.

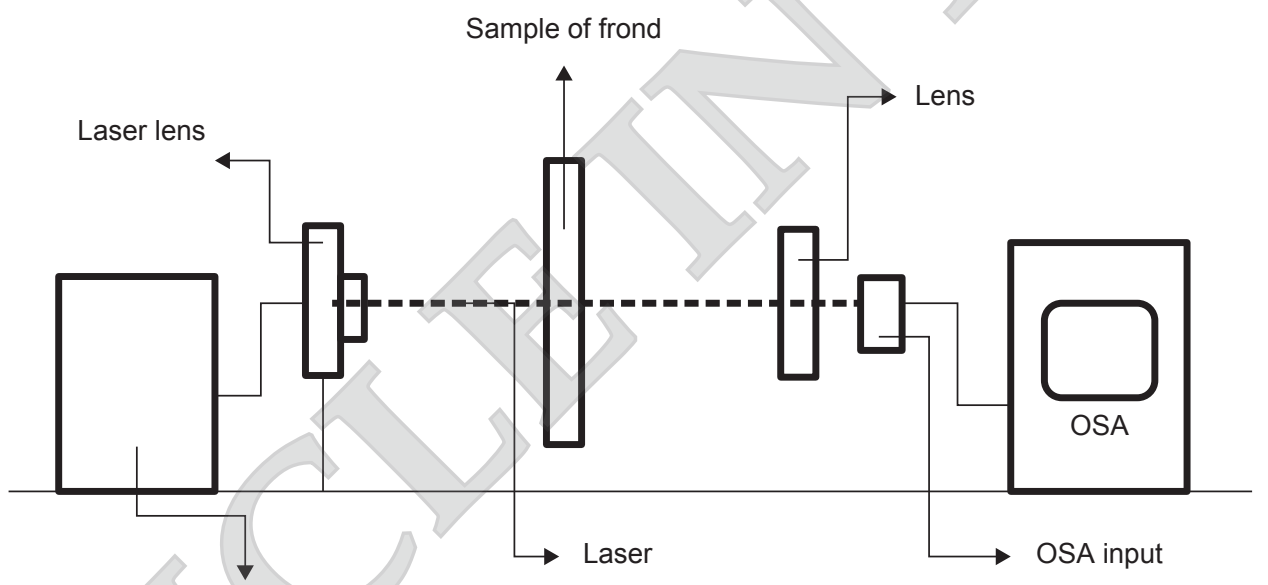

Supercontinuum laser system

Figure 2. Diagram of absorption characteristic experimental setup.

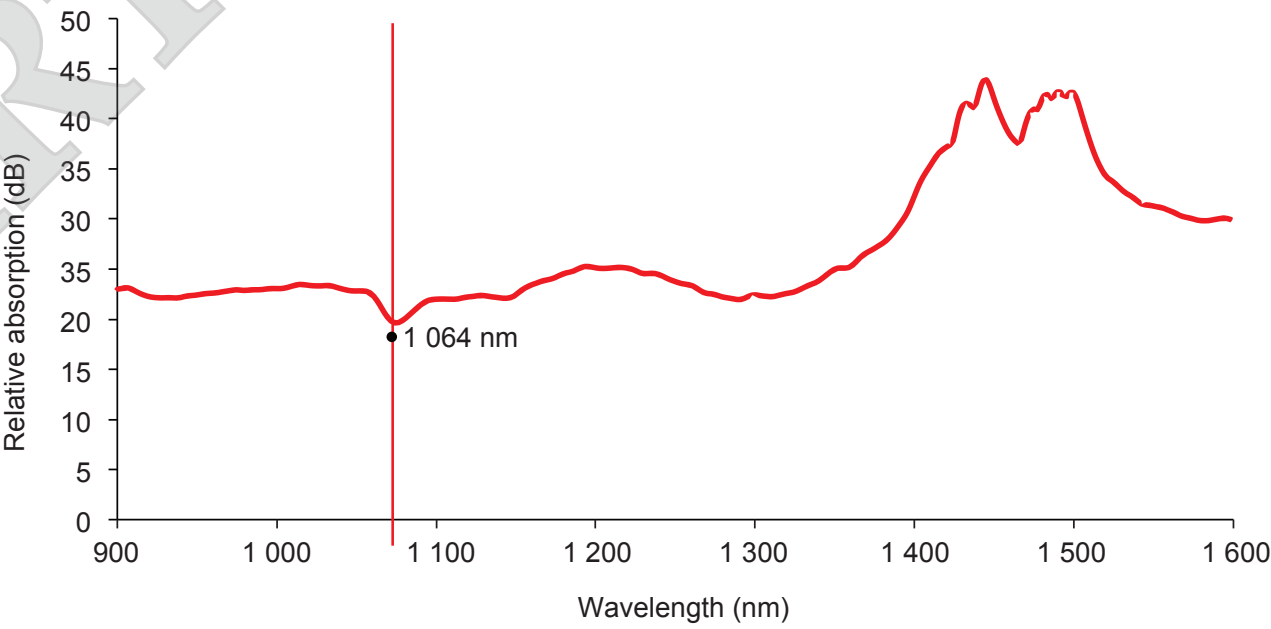

Figure 3. Relative absorption of palm oil frond sample at $1064 \mathrm{~nm}$ wavelength. 


\section{Sample Collection for Cutting of Oil Palm Frond}

Samples of oil palm frond were randomly taken fresh within the same oil palm plantation. Preserving the freshness of the fronds was important as to mimic the moisture condition at the field for the cutting process in the laboratory. The size of the fronds was approximately $30 \mathrm{~cm}$ in length with average width of 55-66 $\mathrm{mm}$ and thickness of $35-45 \mathrm{~mm}$. These dimensions were chosen to ease sample placement onto the limited space of the test platform at the motorised stage.

\section{Experimental Setup}

The experimental configuration of oil palm frond cutting using pulsed fibre laser at $1064 \mathrm{~nm}$ is depicted in Figure 4. Two focus lenses were used: 63$\mathrm{mm}$ and 250-mm focus lenses. Theoretically, by using a short focal length lens $(63 \mathrm{~mm})$, the focusing will be tighter, resulting in smaller spot size. However, the tighter the focusing gradient, the faster the beam was defocused. Therefore, the tolerance was much shorter as compared to the longer focal length lens $(250 \mathrm{~mm})$. Due to the different focal lengths, the intensity profile of the two lenses was different from each other. The distance between the target material and the lens was adjusted using a motorised vertical movement stage to ensure ablation at the focal point. The system was operated using an EZCAD programme with a central processing unit that allowed users to monitor key laser marking parameters, such as speed, frequency and power. The pulse fibre laser employed for this experiment had an emission wavelength of $1064 \mathrm{~nm}$, an average power capacity of 50 Watt, and maximum pulse energy of $1 \mathrm{~mJ}$. The sample was mounted on a test platform underneath the lens to evaluate the cutting characteristics of the laser.

\section{RESULTS AND DISCUSSION}

\section{Performance of Cutting Rate using Pulse Fibre Laser}

Figure $5 a$ shows one of the frond samples during the laser cutting process. The working principle of lasers on oil palm fronds is by initiating a laser beam on the surface of the material and linear movement of the laser. The frond was horizontally placed on the motorised stage in which its distance from lens was optimised beforehand. A stop-watch was employed to record the time taken for this cutting process. The laser pulse frequency was varied to obtain different pulse energy at maximum average optical power. By selecting different operating frequency, the difference in depth of cutting could be observed on the frond Figure $5 b$.

The depth of cutting could be observed and estimated at the cross-section (Figure 6). The resulting energy per pulse was determined by dividing the average power, $P_{A V}$ (Watts) by the repetition rate, $R_{\text {Rate }}$ in pulse per second $(\mathrm{Hz})$. The energy was measured as shown in Equation (1). The resultant quantity was the energy, in Joules, contained in each laser pulse. The result was compared with others biomaterials (Figure 7).

$$
\hat{E}=\frac{P_{A V}}{R_{\text {Rate }}}
$$

The comparative energy of laser cutting to palm fronds with other materials such as Oak and Birch (Aniszewska et al., 2020) was to ensure that the study was carried out in accordance with the trend of laser energy that operated at the predetermined specific parameters throughout the test conducted.

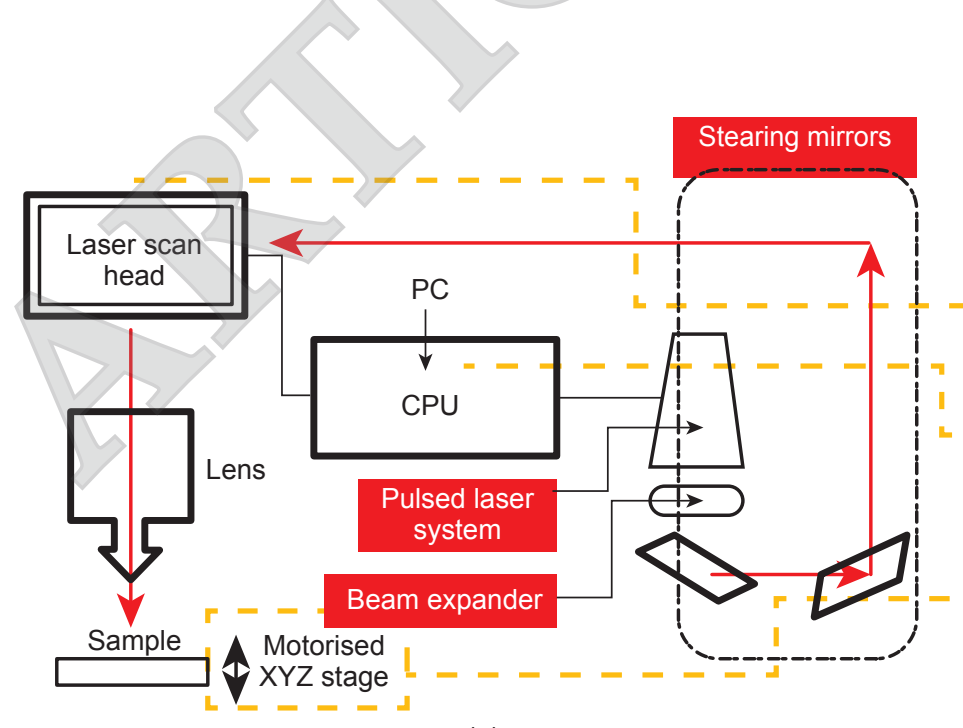

(a)

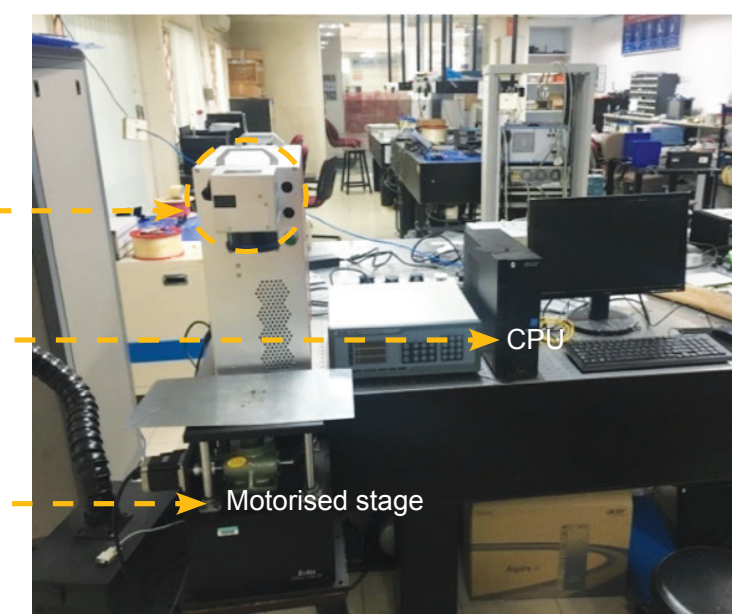

(b)

Figure 4. (a) Diagram of experimental setup of laser system, and (b) the setting of a pulsed laser system. 


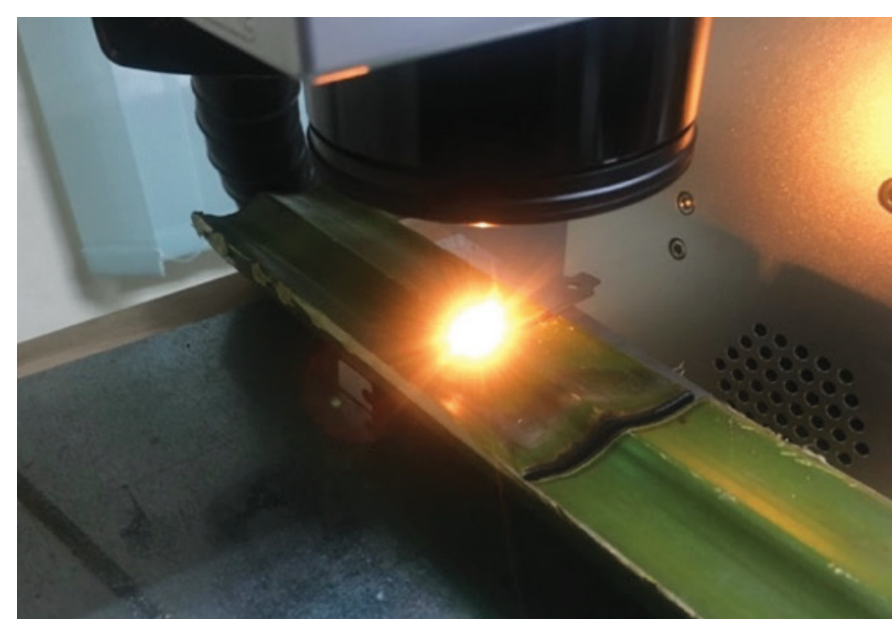

(a)

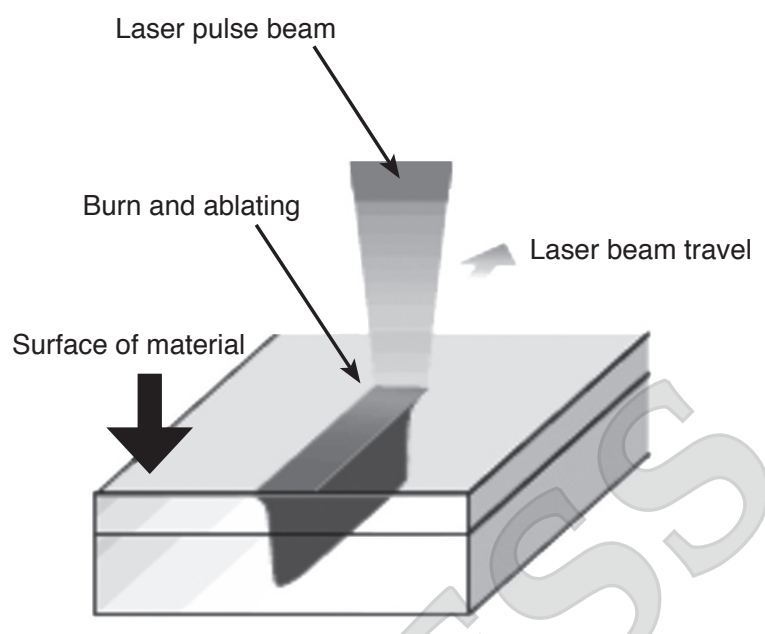

(b)

Figure 5. (a) The laser cutting process to the sample of frond and (b) three parameters: frequency, power and speed; play critical roles in determining the quality and efficiency of the laser cutting.

The cutting performance of the two lenses was determined through their respective cutting rate. The cutting rate was measured by dividing the cutting depth with the total time taken as shown in Equation (2):

$$
\mathrm{R}=\frac{L_{C}}{t_{C}}
$$

where $\mathrm{R}$ is the cutting rate, $L_{c}$ is the depth of cutting $(\mathrm{mm})$, and $t_{c}$ is the time taken for cutting (s). The resulting cutting rates for each laser cutting at certain depths were measured in $\mathrm{mm} / \mathrm{s}$. In this work, cutting depth was measured using a standard ruler and by dividing the fringe crossed into sliced parts.

Twelve frond samples were selected to assess the cutting rate. A total of three cutting tests per sample

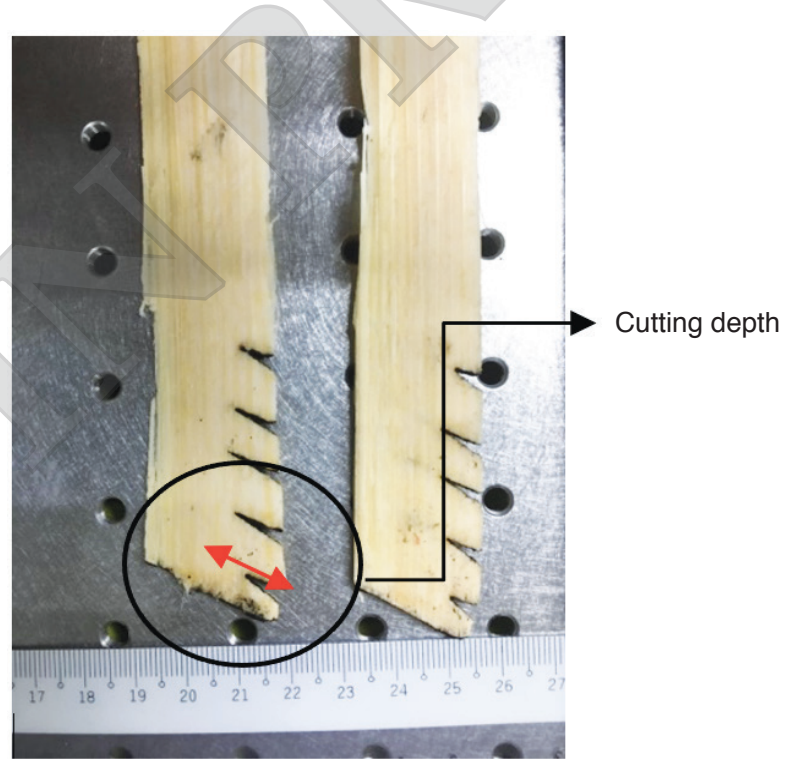

Figure 6. The slice of fronds with cutting depth.

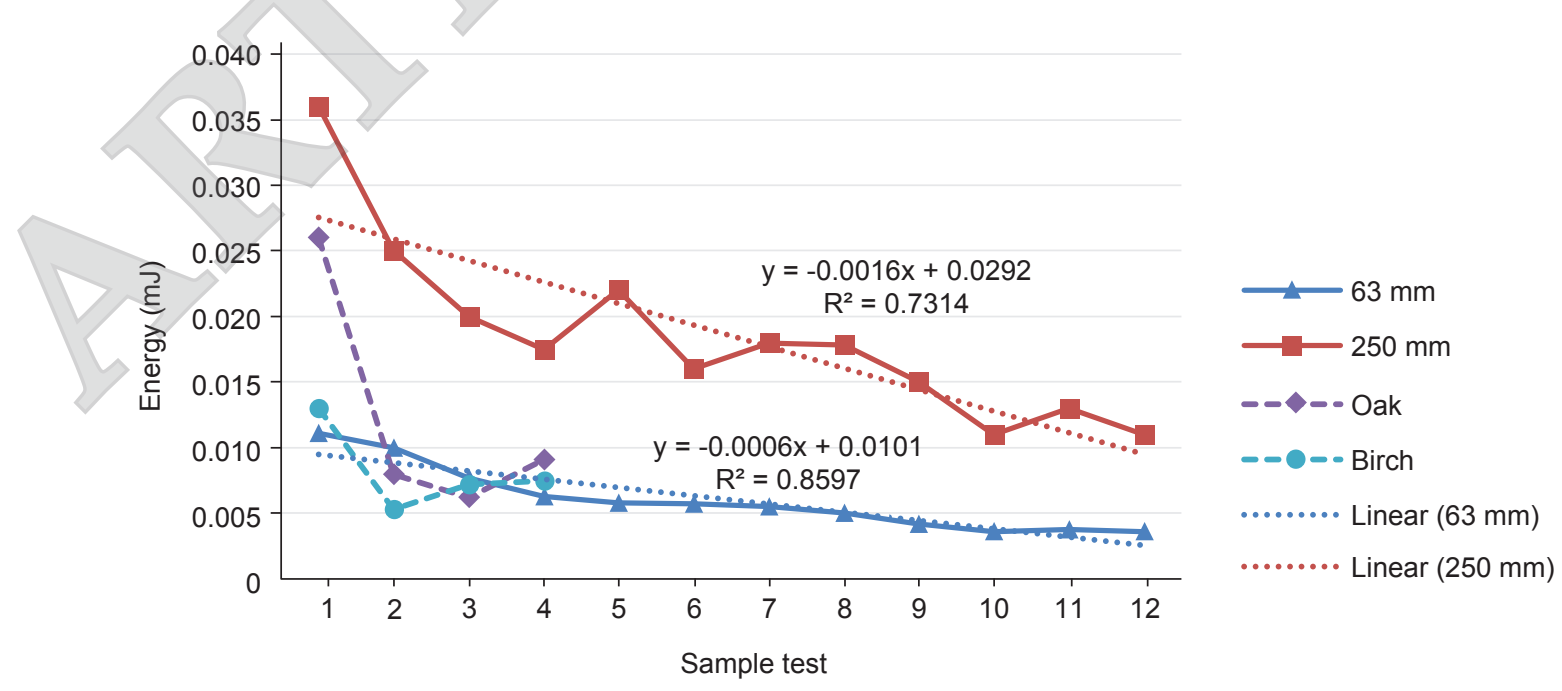

Figure 7. The energy of the laser cutting trend in sample of palm fronds compared to other biomaterials. 
of oil palm frond were conducted and an average of three cutting depths were measured for the cutting rate analysis (Table 1). The cross-section of the palm slice of the sample was examined to identify the depth of cutting as represented by the red arrow (Figure 8).

The laser's applied frequency during the test was within the range of $10-600 \mathrm{kHz}$. However, after running some preliminary tests, it was found that the frequency above $700 \mathrm{kHz}$ produced an instable emission and thus, the upper frequency limit was capped at $600 \mathrm{kHz}$. In this experiment, 12 frond samples were tested by each focus lens with cutting time fixed at $60 \mathrm{~s}$. For each repetition of rate frequency, the frond was cut three times at different locations and the average cutting rate was derived based on these three reading values. Figure 8 depicts the average cutting rate at different repetition rate frequency for $63 \mathrm{~mm}$ and $250 \mathrm{~mm}$ focus lens.
Based on Figure 8, the $63 \mathrm{~mm}$ focus lens yielded a higher cutting rate as compared to $250 \mathrm{~mm}$ despite the variation in pulse energy. The highest cutting rate achieved using the $63 \mathrm{~mm}$ focus lens was 0.47 $\mathrm{mm} / \mathrm{s}$ with an operating frequency of $500 \mathrm{kHz}$ while the $250 \mathrm{~mm}$ lens only managed a cutting rate of only $0.15 \mathrm{~mm} / \mathrm{s}$ at $600 \mathrm{kHz}$. This observation was due to the shorter focal length of $63 \mathrm{~mm}$ focal lens that led to a smaller laser spot beam, in which the intensity per unit area was greater by a factor of $\sim 60$. By comparing the cutting rate, the $63 \mathrm{~mm}$ focus lens was concluded to be more efficient in cutting oil palm. Another observation worth noting was that the cutting rate was significantly reduced beyond $500 \mathrm{kHz}$ for both lenses (indicated within the red boxed in Figure 7). This could be due to the heating effect on the focusing lens as no active cooling was applied, thus, disrupting the effective focal length of the lens.

TABLE 1. THE MEASUREMENT OF CUTTING PERFORMANCE

\begin{tabular}{|c|c|c|c|c|c|c|c|}
\hline \multirow{2}{*}{ No. } & \multirow{2}{*}{$\begin{array}{c}\text { Frequency } \\
(\mathrm{kHz})\end{array}$} & \multirow{2}{*}{$\begin{array}{l}\text { Power } \\
\text { (Watt) }\end{array}$} & \multicolumn{2}{|c|}{ Focus lens $(250 \mathrm{~mm})$} & \multicolumn{2}{|c|}{ Focus lens (63 mm) } & \multirow{2}{*}{$\begin{array}{c}\text { Time taken } \\
\text { (s) }\end{array}$} \\
\hline & & & $\mathrm{CD}(\mathrm{mm})$ & $\mathrm{CR}(\mathrm{mm} / \mathrm{s})$ & $\mathrm{CD}(\mathrm{mm})$ & $\mathrm{CR}(\mathrm{mm} / \mathrm{s})$ & \\
\hline 1 & 50 & 50 & 1.4 & 0.046 & 4.5 & 0.150 & 30 \\
\hline 2 & 100 & 50 & 2.0 & 0.067 & 5.0 & 0.166 & 30 \\
\hline 3 & 150 & 50 & 2.5 & 0.083 & 6.5 & 0.216 & 30 \\
\hline 4 & 200 & 50 & 2.7 & 0.090 & 8.0 & 0.266 & 30 \\
\hline 5 & 250 & 50 & 2.3 & 0.076 & 8.5 & 0.283 & 30 \\
\hline 6 & 300 & 50 & 3.0 & 0.100 & 8.8 & 0.293 & 30 \\
\hline 7 & 350 & 50 & 2.75 & 0.092 & 9.0 & 0.300 & 30 \\
\hline 8 & 400 & 50 & 2.80 & 0.093 & 10.0 & 0.333 & 30 \\
\hline 9 & 450 & 50 & 3.25 & 0.108 & 12.0 & 0.400 & 30 \\
\hline 10 & 500 & 50 & 4.25 & 0.142 & 14.0 & 0.466 & 30 \\
\hline 11 & 550 & 50 & 3.75 & 0.125 & 13.0 & 0.433 & 30 \\
\hline 12 & 600 & 50 & 4.50 & 0.150 & 13.8 & 0.460 & 30 \\
\hline
\end{tabular}

Note: CD - cutting depth; $C R$ - cutting rate.

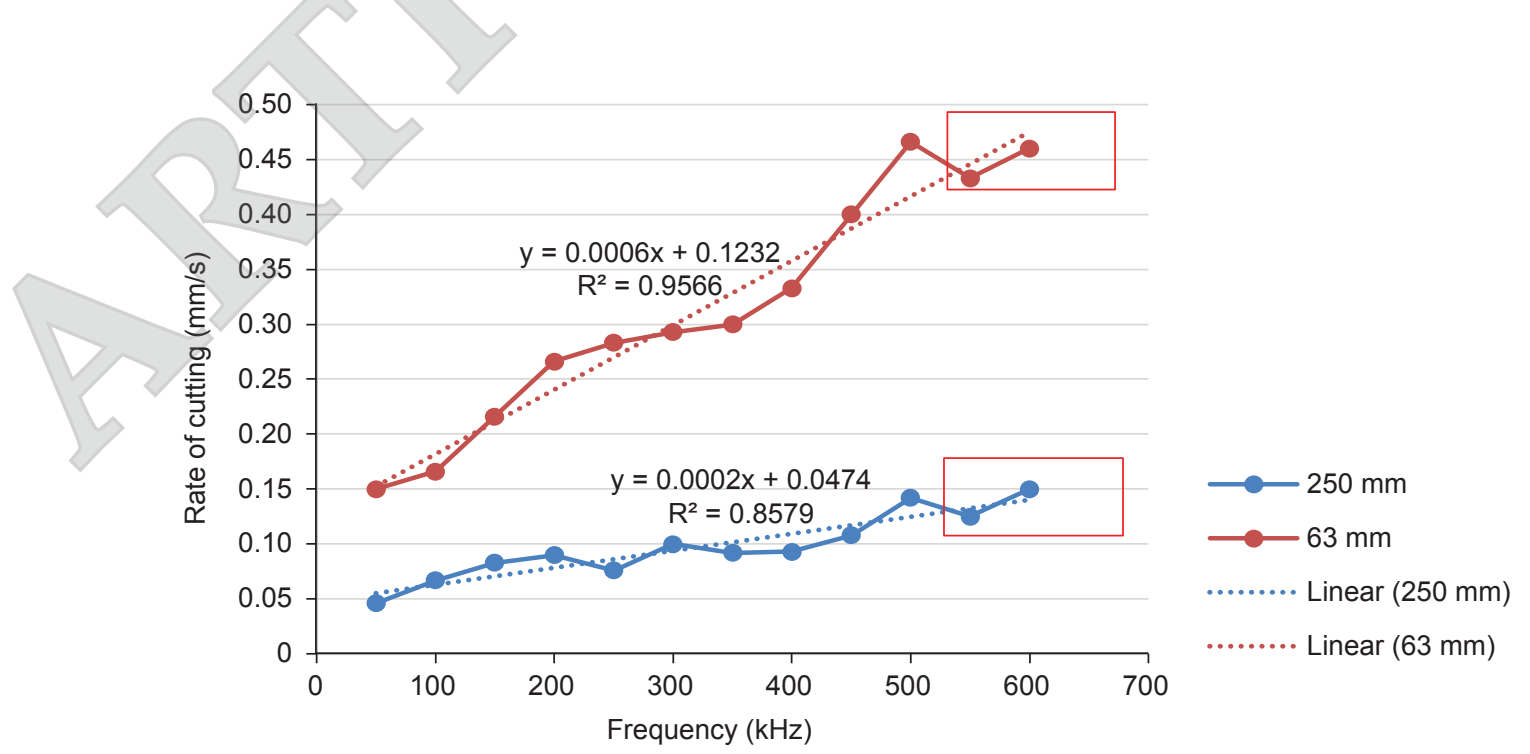

Figure 8. Performance of pulse fibre laser system with $63 \mathrm{~mm}$ and $250 \mathrm{~mm}$ focus lenses. 
Performance of Complete Frond Cutting with $63 \mathrm{~mm}$ Focus Lens

Further assessment of the oil palm frond laser cutting performance using the $63 \mathrm{~mm}$ focus lens was carried out by investigating its capability in making complete frond cuts. With the same laser parameters previously applied, the experiment was replicated to cut through another sample of oil palm frond with a width of $55 \mathrm{~mm}$ and $35 \mathrm{~mm}$ thickness. Figure 9 shows the oil palm fronds that have been completely cut through using a pulse fibre laser system. The total time taken for one complete cut is summarised in Table 2.

As listed in Table 2, the cutting time with applied energy of $0.01 \mathrm{~mJ} /$ pulse was consistent with an average cutting time of $342 \pm 10.4 \mathrm{~s}$, and the average cutting rate was $0.1024 \mathrm{~mm} / \mathrm{s}$. The cutting time recorded varied from one another due to the shape of the oil palm fronds which tapered from the base to both ends. Despite the natural tapering thickness, the cutting rate was constant for each of the test. The consistency of the cutting rate on several frond samples proved that the system was reliable and predictable, making it feasible to be integrated in a harvesting mechanism.

A small scale of combustion and ignition of fire on the surface of the palm fronds was observed during laser operation at higher frequencies beyond $400 \mathrm{kHz}$. However, at lower frequency operation with maximum pulse energy, no such ignition of fire was observed. Such occurrence happens as the pulsed laser has smaller 'heat affected zones' as compared with a CW laser. The energy of the pulsed laser was effectively involved in the cutting process and thus, not much residual energy was left to transfer to the surrounding. From the results discussed, the laser cutting method has the potential to cut the oil palm fronds, and the potential to be developed as harvesting tools. Cutting speed is important to be considered as the main factor for the purpose of harvesting.

In this study, the assumption is that the weight of palm fronds helps the laser cutting process. The cutting force may come from the energy per pulse when hitting the surface of the sample. The frequent energy hitting the biomaterial surface makes the engraving and cutting processes easier due to the help of gravitational weight of oil palm fronds. From this research, in conclusion, laser cutting on palm fronds is possible but at the current available setup, there are limitations to the laser power. Further scaling up the laser power will allow a better and faster cutting performance. Given the speed of development of laser technology currently, it is envisaged that a smaller and compact, yet highly efficient high power laser system will be available for laser cutting palm fronds and will be possibly more effective against the current conventional methods. The time taken for the cutting task using motorised cutter attached with either sickle or chisel for example is within 6-10 s depending on the skills of the labour (Jelani et al., 2018). Table 3 shows the comparison of cutting time by using different methods of harvesting.

The pulsed laser system operating at $1064 \mathrm{~nm}$ was capable to cut oil palm fronds using a $63 \mathrm{~mm}$ focus lens and these parameters determined the intensity of the laser at a given time and also time taken to cut through the fronds. Based on the results obtained, higher power and frequency at low speed will give better laser cutting performance. With a shorter focal distance, lesser loss was experienced by the focused beam from laser. However, the cutting time of this pulsed fibre laser is still too slow compared to

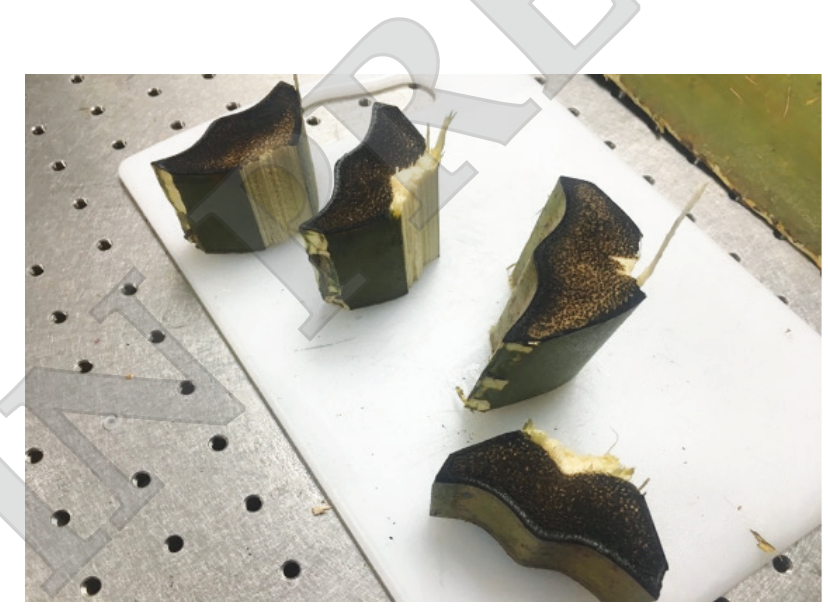

Figure 9. The sample of cut oil palm fronds.

TABLE 2. THE AVERAGE TIME OF COMPLETELY CUTTING AN OIL PALM FROND

\begin{tabular}{ccc}
\hline No. of test & Time (s) & $\mathbf{R}(\mathbf{m m} / \mathbf{s})$ \\
\hline 1 & 320 & 0.109 \\
2 & 340 & 0.103 \\
3 & 360 & 0.097 \\
4 & 350 & 0.100 \\
5 & 340 & 0.103 \\
\hline
\end{tabular}

Note: Average - $342 \pm 10.4 \mathrm{~s}$; average rate of cutting - 0.1024; energy $-0.01 \mathrm{~mJ} /$ pulse.

TABLE 3. THE COMPARISON OF CUTTING TIME USING LASER WITH OTHER HARVESTING METHODS

\begin{tabular}{lcc}
\hline Harvesting methods & \multicolumn{2}{c}{ Average cutting time (s) } \\
\hline & Cut palm bunch & Cut palm fronds \\
\hline Manual $^{*}$ & 55 & 65 \\
Motorised cutter* $^{* *}$ & 10 & 6 \\
Mechanical harvester $^{* * *}$ & 35 & 30 \\
Laser (lab test) & - & 342 \\
\hline
\end{tabular}

Note: * (Saibani et al., 2015); ** (Jelani et al., 2018) and ** (Mohd and Abd Rahim, 2014). 
conventional methods of cutting oil palm fronds. As shown in Table 3, the laser cutting method took the longest amount of time for cut a frond, which was around five times longer in comparison with manual harvesting method. Among the harvesting methods listed, laser harvesting is far behind compared to the others in terms of cutting time. However, this study was still at the preliminary stage, and the main objective of this study which was to find out whether laser cutting has the potential to be used in oil palm harvesting. The fact that the frond was able to be cut has shown a promising potential of this technology and achieved the objective of the study at this current stage. The next step of this study is to try and cut a palm bunch and further optimise the laser setting so that the frond cutting time can be reduced and thus increase its efficiency.

Hence there are many technical issues that need to be further explored, before it can be pushed as an alternative harvesting technology. It was also found that, the enhancement of laser cutting system via power amplification must be increased from the current 50 Watt or $1 \mathrm{~mJ}$ of energy and it is therefore suggested to increase the power up to 100 Watt or above, so that faster cutting time can be achieved.

\section{CONCLUSION}

The main focus of this work is to assess the ability and potential of using pulsed fibre laser technology in cutting oil palm fronds. This was achieved by assessing the effects of power, speed, and frequency on time taken to cut through a frond sample. Two focus lenses were investigated: $63 \mathrm{~mm}$ and 250 $\mathrm{mm}$. The cutting performance of both lenses was evaluated based on cutting rate. Two different focal length lenses have been tested, with $63 \mathrm{~mm}$ lens giving significant improvement of cutting results in terms of precision, sharpness and depth of cutting. With the $63 \mathrm{~mm}$ focus lens, better cutting rate was achieved with power, speed and frequency of $100 \%, 1 \mathrm{~mm} / \mathrm{s}$, and $500 \mathrm{kHz}$, respectively. Due to the shorter focal length, the $63 \mathrm{~mm}$ focus lens was able to uphold laser energy intensity and stability at higher frequencies. The same lens was also tested to perform complete oil frond cuts, yielding consistent results with an average cutting rate of $0.1024 \mathrm{~mm} / \mathrm{s}$. Despite the good potential for laser cutting, the cutting time achieved was still too slow compared to conventional methods. Thus, further experiments are encouraged to look into better ways to enhance the speed of the laser cutting.

\section{ACKNOWLEDGEMENT}

The authors would like to express their sincere gratitude and appreciation to the Malaysian Palm
Oil Board (MPOB) for giving the permission to publish this article. Gratitude is also extended to Universiti Putra Malaysia (UPM) for their full support in allowing access to their facilities for this research.

\section{REFERENCES}

Ali, M M; Hashim, N and Hamid, A S A (2020). Combination of laser-light backscattering imaging and computer vision for rapid determination of oil palm fresh fruit bunches maturity. Comput. Electron. Agric., 169: 105235.

Aniszewska, M; Maciak, A; Zychowicz, W; Zowczak, W; Mühlke, T; Christoph, B; Lamrini, S and Sujecki, S (2020). Infrared laser application to wood cutting. Materials (Basel), 13(22): 5222.

Azaman, M I H; Mahdi, M A; Jelani, A R; Ahmad, M R and Shuib, A R (2019). The potentials of laser cutting technologies for oil palm harvesting. Oil Palm Bulletin, 77: 19-25.

Caprino, G and Tagliaferri, V (1988). Maximum cutting speed in laser cutting of fibre reinforced plastics. Int. J. Mach. Tools Manuf., 28(4): 389-398.

Cenna, A A and Mathew, P (2002). Analysis and prediction of laser cutting parameters of fibre reinforced plastics (FRP) composite materials. Int. J. Mach. Tools Manuf., 42(1): 105-113.

Chen, J K; Beraun, J E and Tham, C L (2004). Ultrafast thermoelasticity for short-pulse laser heating. Int. J. Eng. Sci., 42(8-9): 793-807.

Dawson, T P; Curran, P J and Plummer, S E (1998). Liberty-Modeling the effects of leaf biochemical concentration on reflectance spectra. Remote Sens. Environ., 65(1): 50-60.

Eltawahni, H A; Rossini, N S; Dassisti, M; Alrashed, K; Aldaham, T A; Benyounis, K Y and Olabi, A-G (2013). Evalaution and optimization of laser cutting parametersfor plywood materials. Opt. Lasers Eng., 51(9): 1029-1043.

Heiderscheit, T; Shen, N; Wang, Q; Samanta, A; Wu, B and Ding, H (2019). Keyhole cutting of carbon fiber reinforced polymer using a long-duration nanosecond pulse laser. Opt. Lasers Eng., 120: 101109.

Ismail, A; Ahmad, S M and Sharudin, S Z (2015). Labour productivity in the Malaysian oil palm plantation sector. Oil Palm Ind. Econ. J., 15(2): $1-10$. 
Jelani, A R; Shuib, A R; Hitam, A; Jamak, J and Noor, M M (2003). Hand-held mechanical cutter. $M P O B$ Information Series No. 180.

Jelani, A R; Ahmad, M R; Azaman, M I H; Gono, Y; Mohamed, Z; Sukawai, S; Aduka, A; Aziz, A; Bakri, A; Mohamed, A and Selamat, M B (2018). Development and evaluation of a new generation oil palm motorised cutter (Cantas Evo). J. Oil Palm Res., 30(2): 276-288.

Kushairi, A; Ong-Abdullah, M; Nambiappan, B; Hishamuddin, E; Bidin, M; Ghazali, R; Subramaniam, V; Sundram, S and Parveez, G K A (2019). Oil palm economic performance in Malaysia and R\&D progress in 2018. J. Oil Palm Res, 31(2): 165-194.

Liu, J; Hu, Y; Xu, X and Li, P (2011). Feasibility and influencing factors of laser cutting of tomato peduncles for robotic harvesting. Afr. J. Biotechnol., 10(69): 15552-15563.

Mohd, R K and Abd Rahim, S (2014). Field evaluation of harvesting machines for tall oil palms. J. Oil Palm Res., 26(2): 125-132.

Niyibizi, A; Kioni, P N and Ikua, B G (2014). Recent developments in laser sources for industrial applications. Proc. of the 2013 Mech. Eng. Conf. Sust. Res. Innov., 5: 24-26.

Ottemer, X and Colton, J S (2002). Effects of aging on epoxy-based rapid tooling materials. Rapid Prototyp. J., 8(4): 215-223.

Parvin, P; Shoursheini, S Z; Khalilinejad, F; Bavali, A; Gosha, M M and Mansouri, B (2012). Simultaneous fluorescence and breakdown spectroscopy of fresh and aging transformer oil immersed in paper using ArF excimer laser. Opt. Lasers Eng., 50(11): 16721676.

Quintero, F; Riveiro, A; Lusquiños, F; Comesaña, R and Pou, J (2011). Feasibility study on laser cutting of phenolic resin boards. Phys. Procedia, 12: 578-583.

Saibani, N; Muhamed, A A; Maliami, M F and Ahmad, R (2015). Time and motion studies of manual harvesting methods for oil palm fruit bunches: A Malaysian case study. J. Teknol., 74(3). DOI: 10.11113/ jt.v74.4555.

Schou, J; Heisel, T; Nordskov, A; Christensen, S; Jensen, P S; Thestrup, B and Toftmann, B (2002). Quantitative laser cutting of plants. In High-Power Laser Ablation IV. International Society for Optics and Photonics. p. 734-742.

Singh, P; Chatterjee, A; Bhatia, V and Prakash, S (2020). Application of laser biospeckle analysis for assessment of seed priming treatments. Comput. Electron. Agric., 169: 105212.

Steen, W M and Mazumder, J (2010). Laser welding. Laser Material Processing. Forth edition. Springer, London. p. 199-249.

Westphäling, T (2010). Pulsed fiber lasers from NS to MS range and their applications. Phys. Procedia, 5: 125-136.

Yuliansyah, A T and Hirajima, T (2012). Efficacy of hydrothermal treatment for production of solid fuel from oil palm wastes. Resource Management for Sustainable Agriculture (Abrol, A and Sharma, P eds.). IntechOpen. p. 296. 